\title{
Six-month outcomes of corneal crosslinking with dextran-free isotonic riboflavin solution
}

\author{
Resultados após seis meses de crosslinking de córnea com solução isotônica de riboflavina sem dextrano
}

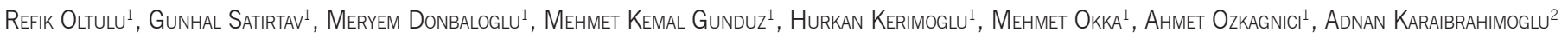

\begin{abstract}
Purpose: To analyze the short-term clinical and topographic outcomes in patients with keratoconus after corneal collagen cross-linking treatment $(\mathrm{CXL})$ with dextran-free isotonic riboflavin solution.

Methods: In this retrospective case series, 26 eyes from 26 patients with keratoconus were studied. The best corrected visual acuity (BCVA) and refractive and topographic findings were analyzed at a 6-month follow-up.

Results: The mean BCVA (Snellen lines) values before and 1, 3, and 6 months after $C X L$ were $0.51 \pm 0.2,0.48 \pm 0.2,0.57 \pm 0.2$, and $0.64 \pm 0.2$, respectively, and the difference between the preoperative and 6-month values was statistically significant $(p=0.006)$. The mean spherical equivalent refraction decreased from $-5.6 \pm 2.4$ diopters $(\mathrm{D})$ preoperatively to $-5.0 \pm 2.1 \mathrm{D}$, and mean simulated keratometry decreased from $48.5 \pm 2.5 \mathrm{D}$ to $47.8 \pm 2.6 \mathrm{D}$ at 6 months. $(p=0.145$ and $p=0.001$ respectively). In addition, the maximum keratometry decreased progressively and significantly from the preoperative value during follow-up $(p=0.003)$. The central and minimal corneal thicknesses, including those of the epithelium, also decreased from $442.8 \pm 25.6 \mu \mathrm{m}$ and $430.5 \pm 23.9 \mu \mathrm{m}$ preoperatively to $420.7 \pm 31.8 \mu \mathrm{m}$ and $409.3 \pm 28.7 \mu \mathrm{m}$ at the most recent follow-up $(p<0.001)$ respectively. No intraoperative or postoperative complications were observed. Conclusions: CXL with dextran-free isotonic riboflavin solution appears to be a safe treatment alternative for keratoconus and yields sustained short-term improvements in visual acuity, keratometric readings, and corneal thickness. However, long-term results are needed to confirm these outcomes.
\end{abstract}

Keywords: Cornea; Collagen; Cross-linking reagents; Riboflavin/therapeutic use; Ultraviolet rays; Dextrans; Visual acuity

\section{RESUMO}

Objetivo: Analisar os resultados clínicos e topográficos curto prazo após crosslinking (CXL) de córnea com solução isotônica de riboflavina sem dextrano, em pacientes com ceratocone.

Método: Estudamos 26 olhos de 26 pacientes com ceratocone, nesta série retrospectiva de casos. Melhor acuidade visual corrigida (BCVA), refração e achados topográficos foram analisados aos 6 meses de acompanhamento.

Resultados: BCVA pré-operatória (linhas de Snellen) foi de 0,51 $\pm 0,2$. BCVA após CXL foram de 0,48 $\pm 0,2,0,57 \pm 0,2$ e 0,64 $\pm 0,2$ no 10, 3e e 60 meses, respectivamente. A diferença entre a BCVA pré-operatória e mais recente foi estatisticamente significativa ( $p=0,006)$. O equivalente esférico médio diminuiu de $-5,6 \pm 2,4$ dioptrias (D) no pré-operatório para $-5.0 \pm 2.1 \mathrm{D}$ e a média da ceratometria simulada diminuiu de 48,5 $\pm 2,5 \mathrm{D}$ para 47,8 $2,6 \mathrm{D}$ aos 6 meses. ( $p=0,145$ e $p=0,001$, respectivamente). A ceratometria máxima diminuiu progressivamente durante o acompanhamento com as mudanças sendo significativamente diferentes do valor pré-operatório $(p=0,003)$. As espessuras corneanas central e mínima, diminuiram de 442,8 $\pm 25,6 \mu \mathrm{m}$ e 430,5 $\pm 23,9 \mu \mathrm{m}$ para 420,7 $\pm 31,8 \mu m e 409,3 \pm 28,7 \mu m$, respectivamente, navisita mais recente $(p<0,001)$. Não foram observadas complicações intraoperatórias e pós-operatórias.

Conclusões: CXL com solução de riboflavina isotônica sem dextrano parece ser uma opção segura de tratamento para o ceratocone com melhora mantida na acuidade visual, ceratometria e espessura corneana, no curto prazo. Resultados a longo prazo são necessários para confirmar estes resultados.

Descritores: Córnea; Colágeno; Reagentes para ligações cruzadas; Riboflavina/uso terapêutico; Raios ultravioleta; Dextranos; Acuidade visual

\section{INTRODUCTION}

Keratoconus is a bilateral, asymmetric, non-inflammatory, and slowly progressive corneal disease with an approximate incidence of 1 in 2000 individuals. This condition is characterized by corneal thinning and protrusion, progressive myopia, and irregular astigmatism $^{(1)}$ and has conventionally been treated using modalities, such as rigid contact lenses, intrastromal corneal ring segment implantation, and keratoplasty. However, current treatment objectives include not only improved visual acuity but also the prevention of disease progression ${ }^{(2)}$. Accordingly, corneal cross-linking $(C X L)$ is a relatively new treatment method designed to increase the mechanical and biochemical strength of the stromal tissue via exposure of the ectatic cornea to riboflavin and ultraviolet-A (UVA) light ${ }^{(3)}$. This procedure is the only currently available semisurgical therapeutic approach for patients with progressing keratoconus and has been shown to delay or even stop the progression of corneal ectasia, thus reducing the need for keratoplasty ${ }^{(4)}$.

A minimum safety limit is defined as $400 \mu \mathrm{m}$ for corneal preoperative thickness to avoid damage of ultraviolet $A$ (UV-A) irradiation to endothelium, lens, and deeper structures ${ }^{(5,6)}$.

Different $C X L$ techniques for thin corneas have been developed, including transepithelial CXL ${ }^{(7)}$ and $C X L$ with customized pachymetric-guided epithelial debridement preserving the epithelium in thinner corneal regions ${ }^{(8)}$. Alternatively, the induction of iatrogenic corneal swelling via the administration of hypo-osmolar riboflavin solutions before CXL application has been proposed as an alternative method for corneas thinner than $400 \mu \mathrm{m}^{(9)}$. However, the duration of thickening induced by hypo-osmolar solutions is controversial, given that some reports indicate a failure of this effect to persist throughout the procedure, thus rendering deeper structures vulnerable to possible
Funding: No specific financial support was available for this study.

Disclosure of potential conflicts of interest: None of the authors have any potential conflicts of interest to disclose.

Corresponding author: Refik Oltulu. Department of Ophthalmology. Meram Faculty of Medicine. Necmettin Erbakan University, Meram, Konya - 42080 - Turkey - E-mail: refikoltulu@gmail.com Approved by the following research ethics committee: Meram Faculty of Medicine, Necmettin Erbakan University (\#4532, June $30^{\text {th }}$ 2014). 
side effects from ultraviolet light exposure towards the end of the procedure ${ }^{(10)}$. Notably, a recently introduced iso-osmolar riboflavin solution that contains hydroxymethylcellulose instead of dextran is considered a possible alternative to hypo-osmolar solutions in cases with thin corneas.

In the present study, changes in visual acuity and refractive and topographic outcomes were analyzed after CXL treatment performed with this newly introduced dextran-free, isotonic riboflavin solution.

\section{METHODS}

Twenty-six eyes of 26 patients (12 males, 14 females; mean age: $25.1 \pm 4.6$ years, range: $18-33$ years) with progressive keratoconus who underwent CXL between September 2012 and October 2013 at Necmettin Erbakan University Meram Faculty of Medicine were included in this study. The local ethics committee approved this study, which adhered to the tenets of Declarations of Helsinki, and informed consent was obtained from all patients. The inclusion criteria were keratoconus with documented progression in the past 12 months, defined as an increase in maximum keratometry (Kmax) of 1.00 diopter (D) or more in the previous 12 months; corneal thickness of at least $400 \mu \mathrm{m}$ at the thinnest point; age of at least 18 years; and patient-reported deterioration of visual acuity (excluding other possible non-corneal reasons for deterioration). The exclusion criteria were corneal opacity, previous ocular surgery, previous herpetic keratitis, active ocular infection, autoimmune disease, chemical injury, delayed epithelial healing, and lactation at the time of the study.

The CXL procedure was performed under sterile conditions in a surgical room according to the following description. After administering $0.5 \%$ propacaine drops (Alcaine; Alcon Pharmaceuticals, Fribourg, Switzerland) as a topical anesthestic, the corneal epithelium was removed by mechanical debridement over the central $8.0 \mathrm{~mm}$. A dextran-free isotonic riboflavin solution [ $>0.1 \%$ riboflavin with $1.1 \%$ hydroxypropylmethylcellulose (MedioCROSS M; Kiel, Germany)] was applied to the cornea every $3 \mathrm{~min}$ for $30 \mathrm{~min}$. After $30 \mathrm{~min}$, UVA (370 nm, $3 \mathrm{~mW} / \mathrm{cm}^{2}$ intensity) was applied to the cornea (CCL-VARIO; Peschke Meditrade $\mathrm{GmbH}$, Huenenberg, Switzerland) for 30 min. Application of the riboflavin solution continued every 3 min during irradiation. Ultrasound pachymetry (OcuScan RxP; Alcon Laboratories, Inc., Fort Worth, TX, USA) was performed on the de-epithelialized cornea at approximately the thinnest point, which had been determined preoperatively from a corneal pachymetry map obtained via corneal topography. Three repeated measurements were taken by the same surgeon (RO) after de-epithelization, at 15, 30, and 45 min into the procedure, and at the end of the procedure. For each, the average of 10 measurements was taken, and the mean value obtained from the 3 measurements was used for the evaluation. Topical anesthetics were added as needed during the procedure. Postoperatively, a bandage contact lens (PureVision (balafilcon A); Bausch \& Lomb, Rochester, NY, USA) was placed, and levofloxacin and dexamethasone eyedrops were administered 4 times daily until epithelization was complete.

At baseline and each of the postoperative follow-up examinations (1, 3, 6 months), all patients underwent ophthalmological evaluations to measure the best corrected visual acuity (BCVA), refraction (spherical equivalent, diopters; D) and corneal topography (Pentacam; Oculus $\mathrm{GmbH}$, Wetzlar, Germany). The preoperative and postoperative K-readings of Kmax and mean simulated keratometry (Sim K) were assessed from topography data.

All variables were found to be normally distributed according to the Kolmogorov-Smirnov test. The statistical power analysis yielded a power of approximately $35 \%$. The Friedman two-way analysis of variance test was used to compare preoperative and postoperative data. Following a Bonferroni correction, a $p$ value of $<0.0083$ was considered statistically significant in comparison tests.

\section{RESULTS}

The mean baseline BCVA was $0.51 \pm 0.2$ (Snellen lines), and the corresponding readings after CXL were $0.48 \pm 0.2,0.57 \pm 0.2$, and $0.64 \pm 0.2$ at the 1-, 3-, and 6-month follow-ups, respectively. A significant difference was observed between the baseline and 6-month postoperative BCVA values ( $p=0.006$; Figure 1). The preoperative mean spherical equivalent (SEQ) refraction was $-5.6 \pm 2.4 \mathrm{D}$; although this parameter decreased to $-5.0 \pm 2.1 \mathrm{D}$ at the last follow-up (SEQ change $=0.59 D)$, this change was not statistically significant $(p=0.145$; Figure 2). In other words, an inverse relationship was observed between the SEQ and BCVA values.

Compared with the baseline, the mean Sim K increased slightly during the first postoperative month ( $p=0.407$ ), followed by a decrease at the 3-month follow-up $(p=0.361)$ and subsequent plateau from $48.5 \pm 2.5 \mathrm{D}$ to $47.8 \pm 2.6 \mathrm{D}$ at the 6 -month follow-up $(p=0.001)$. The mean Kmax exhibited a progressive decrease over 6 months, and this change represented a significant difference from the baseline value $(p=0.003$; Figure 3).

Before surgery, the central corneal thickness (CCT) and minimal corneal thickness (MCT), including the epithelium, were $442.8 \pm$ $25.6 \mu \mathrm{m}$ and $430.5 \pm 23.9 \mu \mathrm{m}$, respectively. These values decreased to $417.6 \pm 31.9 \mu \mathrm{m}$ and $407.2 \pm 31.1 \mu \mathrm{m}$, respectively, at 3 months but subsequently increased to $420.7 \pm 31.8 \mu \mathrm{m}$ and $409.3 \pm 28.7 \mu \mathrm{m}$, respectively at 6 months. Notably, the differences between the preoperative and postoperative CCT and MCT values were statistically significant at every time point during follow-up $(p<0.001$; Figure 4). At baseline, the mean preoperative MCT, including the

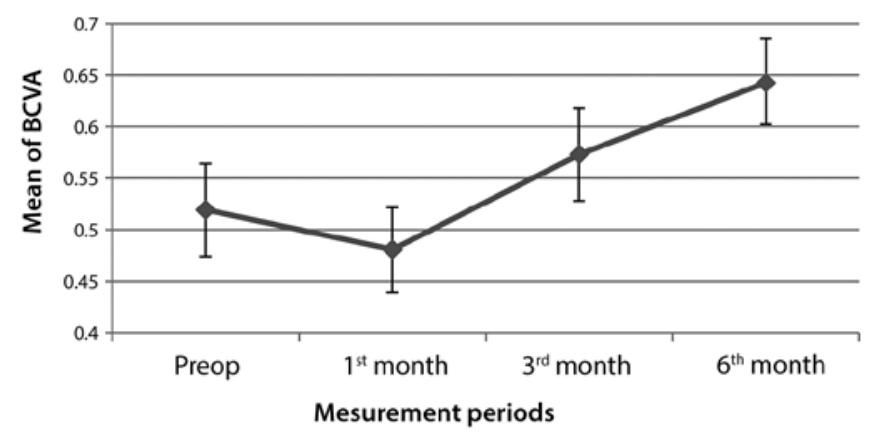

$\mathrm{BCVA}=$ best corrected visual acuity

Figure 1. Graph representing changes in best corrected visual acuity over time.

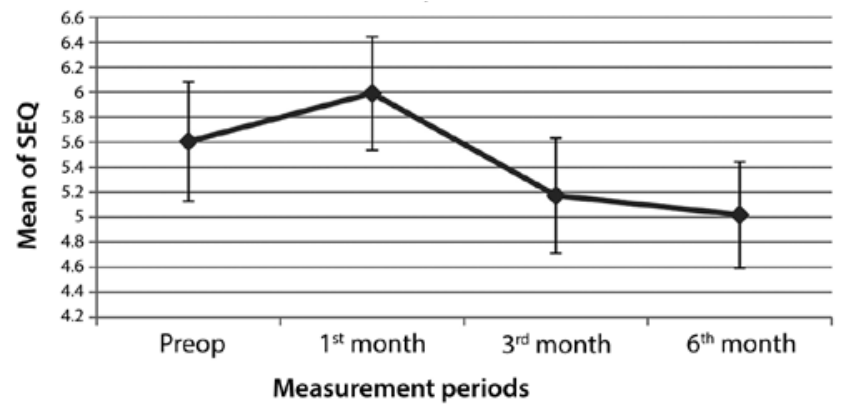

$\mathrm{SEQ}=$ mean spherical equivalent

Figure 2. Graph representing changes in spherical equivalent refractive values of the eyes over time. 
epithelium, measured $430.5 \pm 23.9 \mu$ m; this was reduced to 396.8 $\pm 21.3 \mu \mathrm{m}$ after removal of the epithelium. After the application of dextran-free isotonic riboflavin solution, the MCT exhibited a steady increase at the 15-, 30-, 45-, and 60-min time points during the procedure $(422.3 \pm 19.1 \mu \mathrm{m}, 450.4 \pm 14.9 \mu \mathrm{m}, 459.1 \pm 15.7 \mu \mathrm{m}$, and $464.9 \pm 15.5 \mu \mathrm{m}$, respectively).

No eye exhibited a sterile or infectious infiltrate in the corneal stroma after surgery, and no complications were observed after the application of dextran-free isotonic riboflavin solution. All corneas demonstrated normal progression with respect to the epithelial healing process. At the final follow-up examination ( 6 months after $C X L$ ), all corneas were transparent, with no detectable stromal scarring.

\section{DISCUSSION}

Riboflavin-induced ultraviolet-light CXL has received a significant amount of attention in recent years. Previous studies have demonstrated the safety and efficacy of CXL for preventing the progression of keratoconus ${ }^{(10-12)}$. In this procedure, riboflavin serves as a photosensitizer for crosslink induction and protects the underlying tissues from the deleterious effects of UVA irradiation; in addition, it prevents

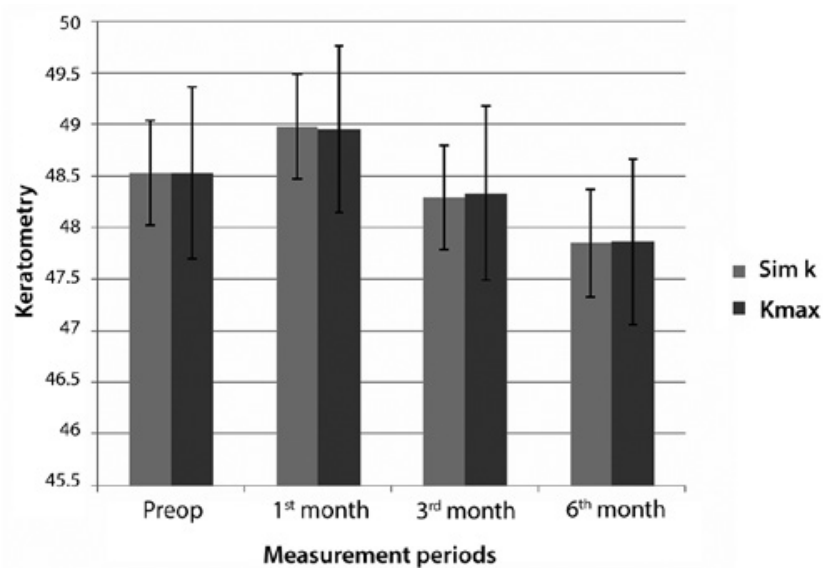

Sim $\mathrm{K}=$ average simulated keratometry; $\mathrm{Kmax}=$ maximal keratometry

Figure 3. Bargraph demonstrating the Kmaxand Sim Kvalues (measures of keratoconus) before surgery and at 1,3, and 6 months after corneal crosslinking.

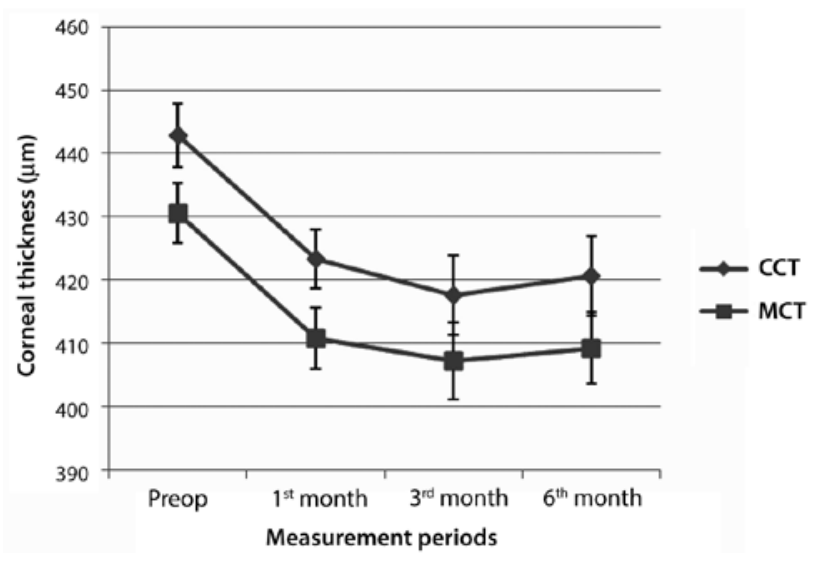

$\mathrm{CCT}=$ central corneal thickness; $\mathrm{MCT}=$ minimal corneal thickness

Figure 4. Changes in the central corneal thickness and minimum corneal thickness measurements over time in patients with keratoconus. corneal dehydration during the operative procedure ${ }^{(13)}$. In cases with particularly thin corneas, a $0.1 \%$ hypo-osmolar riboflavin solution can also be applied to artificially swell the cornea to a thickness of at least $400 \mu \mathrm{m}$ before $\mathrm{CXL}$, thus reducing the risk of UVA-induced endothelial cytotoxicity ${ }^{(9)}$

According to an earlier protocol described by Hafezi et al., UVA treatment was administered after inducing iatrogenic corneal swelling with hypo-osmolar riboflavin solution to a minimum corneal thickness of $400 \mu \mathrm{m}$, a procedure that was found to efficiently increase the stromal thickness by $25 \%$ after $30 \mathrm{~min}^{(9)}$. In this procedure, the application of iso-osmolar riboflavin solution continued during UVA irradiation. This led to concerns regarding the durability of corneal thickness throughout the procedure such as those raised by Kaya et al., who suggested that the iatrogenic swelling induced by a hypo-osmolar riboflavin solution might be short-acting and thus would not persist throughout UVA application, following an observed decrease in the corneal thickness upon the installation of the iso-osmolar riboflavin solution(10).

Previous studies and the standard CXL procedure have generally used an iso-osmolar riboflavin $0.1 \%$ solution containing $20 \%$ dextran (402.7 mOsmol/L), which exerts a temporary dehydrating effect and consequent corneal thinning. In contrast, we performed the CXL procedure with a dextran-free isotonic riboflavin solution and observed that the corneal thickness increased throughout the procedure, in agreement with the results of a previous study ${ }^{(14)}$. However, the safety CXL in the presence of an artificially swollen cornea remains controversial because the lower concentration of collagen fibers in the hydrated stroma is expected to weaken the crosslinking effect of UVA, as demonstrated in experiments with collagen gels ${ }^{(15)}$.

The current study aimed to analyze the variables related to short-term outcomes in a group of patients with keratoconus who were treated via corneal CXL with a dextran-free isotonic riboflavin solution. After an initial worsening of all keratoconus indices and BCVA, likely due to epithelial debridement, continuous improvements were observed in most keratometric and topographic indices for up to 6 months after surgery. In previous studies, BCVA has been reported to improve by 2 Snellen lines at 36 months and 1.05 Snellen lines at 12 months after $\mathrm{CXL}^{(12,16)}$. In another study, Goldich et al. observed a significant improvement in the BCVA $(0.21 \pm 0.1 \text { to } 0.14 \pm 0.1 ; p=0.002)^{(17)}$. Our results demonstrated a significant improvement of 1.03 Snellen lines in the BCVA at 6 months.

A previous study conducted by Wittig-Silva et al. failed to exhibit changes in the SEQ or the spherical or cylindrical component of subjective refraction ${ }^{(18)}$. However, other studies have reported changes in SEQ ranging from $+0.40 \mathrm{D}$ to $+2.13 \mathrm{D}^{(12,19,20)}$. Similarly, Caporossi et al. observed a decrease in the SEQ value of $2.21 \mathrm{D}$ at 3 months after $C X L^{(21)}$, and Wollensak et al. reported a significant improvement of $1.14 \mathrm{D}$ in the average SEQ at 6 months postoperatively ${ }^{(11)}$. In our study, we observed a mean improvement in the SEQ of 0.6 D at the 6-month follow-up; in addition, this was the lowest SEQ observed in this study. However, the change in this parameter failed to reach statistical significance, possibly as a result of the limited number of patients in our study.

With respect to corneal curvature, we observed significant reductions in the mean Kmax and Sim K values of 1.26 and $0.73 \mathrm{D}$, respectively, at 6 months postoperatively. Caporossi et al. reported similar results, with a postoperative average reduction in the mean keratometry measurement of $1.96 \mathrm{D}^{(21)}$. Similarly, Wollensak et al. reported a reduction in the mean keratometry reading of $2.01 \mathrm{D}^{(11)}$.

Similar to previous studies, the corneal thickness decreased from the preoperative to the final time point, indicating corneal compaction ${ }^{(20,22,23)}$. In our study, statistically significant differences between the pre- and postoperative measurements were detected when the corneal thicknesses at the apex of the keratoconus (MCT) and pupil center (CCT) were measured. Notably, the CCT initially decreased significantly from the baseline up to the 3-month time point but exhibited 
significant improvement at the 6-month follow-up. The MCT values similarly decreased from the baseline, although the 6-month value remained significantly below the preoperative value.

To the best of our knowledge, the outcomes of CXL treatment with a dextran-free isotonic riboflavin solution have not been reported previously. This study demonstrated improvements in outcomes related to keratometry and visual acuity in patients undergoing CXL with a dextran-free isotonic riboflavin solution, similar to the improvements observed in patients from previous studies who were treated with dextran-containing solutions. Furthermore, we reported that the use of a dextran-free iso-osmolar riboflavin solution during CXL induced a steady increase in corneal thickness throughout the procedure. This finding might be beneficial with respect to an increased indication for CXL in patients with thin corneas, as it removes the concern of unpredictable intraoperative thinning below the safety margin reported in our other study ${ }^{(14)}$. We note that the improvements in visual acuity and keratometry readings were found to occur progressively throughout the postoperative follow-up period, suggesting that a longer follow-up is needed to determine the total functional and anatomic effects of CXL and to obtain stable functional and keratometric values. The small number of subjects in the study group, lack of a control group comprising patients treated with a standard dextran-containing riboflavin solution, and the short follow-up period were limitations of our present study.

In conclusion, this study has demonstrated the safety of CXL with a dextran-free isotonic riboflavin solution for the treatment keratoconus. This procedure was found to yield good visual results and to reduce disease progression, as well as iso-osmolar solutions containing dextran.

\section{REFERENCES}

1. Rabinowitz YS. Keratoconus. Surv Ophthalmol. 1998;42(4):297-319.

2. Jhanji V, Sharma N, Vajpayee RB. Management of keratoconus: current scenario. Br J Ophthalmol. 2011;95(8):1044-50

3. Sedaghat M, Naderi M, Zarei-Ghanavati M. Biomechanical parameters of the cornea after collagen crosslinking measured by waveform analysis. J Cataract Refract Surg. 2010; 36(10):1728-31

4. Raiskup-Wolf F, Hoyer A, Spoerl E, Pillunat LE. Collagen cross-linking with riboflavin and ultraviolet-A light in keratoconus: long-term results. J Cataract Refract Surg. 2008; 34(5):796-801.

5. Wollensak G, Spoerl E, Wilsch M, SeilerT. Endothelial cell damage after riboflavin-ultraviolet-A treatment in the rabbit. J Cataract Refract Surg. 2003;29(9):1786-90.

6. Wollensak G, Spoerl E, Wilsch M, Seiler T. Keratocyte apoptosis after corneal collagen cross-linking using riboflavin/UVA treatment. Cornea. 2004;23(1):43-9.
7. Çerman E, Toker E, Ozarslan Ozcan D. Transepithelial versus epithelium-off crosslinking in adults with progressive keratoconus. J Cataract Refract Surg. 2015:41(7):1416-25.

8. Kymionis GD, Diakonis VF, Coskunseven E, Jankov M, Yoo SH, Pallikaris IG. Customized pachymetric guided epithelial debridement for corneal collagen cross linking. BMC Ophthalmol. 2009;9:10-4

9. Hafezi F, Mrochen M, Iseli HP, Seiler T. Collagen crosslinking with ultraviolet-A and hypoosmolar riboflavin solution in thin corneas. J Cataract Refract Surg. 2009;35(4): 621-4.

10. Kaya V, Utine CA, Yılmaz ÖF. Intraoperative corneal thickness measurements during corneal collagen cross-linking with hypoosmolar riboflavin solution in thin corneas. Cornea. 2012;31(5):486-90. Comment in: Cornea. 2012;31(12):1508-9; Cornea. 2013; 32(1):110

11. Wollensak G, Spoerl E, Seiler T. Riboflavin/ultraviolet-a-reduced collagen crosslinking for the treatment of keratoconus. Am J Ophthalmol. 2003;135(5):620-7.

12. Hersh PS, Greenstein SA, Fry KL. Corneal collagen crosslinking for keratoconus and corneal ectasia: one-year results. J Cataract Refract Surg. 2011;37(1):149-60.

13. Caporossi A, Mazzotta C, Baiocchi S, Caporossi T. Long-term results of riboflavin ultraviolet a corneal collagen cross-linking for keratoconus in Italy: the Siena eye cross study. Am J Ophthalmol. 2010;149(4):585-93.

14. Oltulu R, Şatirtav G, Donbaloğlu M, Kerimoğlu H, Özkağnici A, Karaibrahimoğlu A. Intraoperative corneal thickness monitoring during corneal collagen cross-linking with isotonic riboflavin solution with and without dextran. Cornea. 2014;33(11):1164-7.

15. Ahearne M,Yang Y, Then KY, Liu KK. Non-destructive mechanical characterisation of UVA/riboflavin crosslinked collagen hydrogels. Br J Ophthalmol. 2008;92(2):268-71.

16. O'Brart DP, Kwong TQ, Patel P, McDonald RJ, O'Brart NA. Long-term follow-up of riboflavin/ultraviolet A $(370 \mathrm{~nm})$ corneal collagen cross-linking to halt the progression of keratoconus. Br J Ophthalmol. 2013:97(4):433-7.

17. Goldich Y, Marcovich AL, Barkana Y, Mandel Y, Hirsh A, Morad Y, et al. Clinical and corneal biomechanical changes after collagen cross-linking with riboflavin and UV irradiation in patients with progressive keratoconus: results after 2 years of follow-up. Cornea. 2012;31(6):609-14.

18. Wittig-Silva C, Chan E, Islam FM, Wu T, Whiting M, Snibson GR. A randomized, controlled trial of corneal collagen cross-linking in progressive keratoconus: three-year results. Ophthalmology. 2014;121(4):812-21

19. Vinciguerra R, Romano MR, Camesasca Fl, Azzolini C, Trazza S, Morenghi E, et al. Corneal cross-linking as a treatment for keratoconus: four-year morphologic and clinical outcomes with respect to patient age. Ophthalmology. 2013;120(5):908-16.

20. Vinciguerra P, Albe E, Trazza S, Rosetta P, Vinciguerra R, Seiler T, et al. Refractive, topographic, tomographic, and aberrometric analysis of keratoconic eyes undergoing corneal cross-linking. Ophthalmology. 2009;116(3):369-78.

21. Caporossi A, Baiocchi S, Mazzotta C, Traversi C, Caporossi T. Parasurgical therapy for keratoconus by riboflavin-ultraviolet type $A$ rays induced cross-linking of corneal collagen. J Cataract Refract Surg. 2006;32(5):837-45. Comment in: J Cataract Refract Surg. 2007;33(7):1143-4; author reply 1144

22. Greenstein SA, Shah VP, Fry KL. Corneal thickness changes after corneal collagen crosslinking for keratoconus and corneal ectasia: one-year results. J Cataract Refract Surg 2011;37(4):691-700.

23. Vinciguerra P, Albe E, Trazza S, Seiler T, Epstein D. Intraoperative and post-operative effects of corneal collagen cross-linking on progressive keratoconus. Arch Ophthalmol. 2009:127(10):1258-65 